\title{
A DISTRIBUIÇÃO NATURAL DO PINHEIRO-DO-PARANÁ NO ESTADO DO RIO GRANDE DO SUL, BRASIL: A INFLUÊNCIA DE FATORES CLIMÁTICOS
}

\author{
FRITZSONS, Elenice - elenice.fritzsons@embrapa.br \\ Empresa Brasileira de Pesquisa Agropecuária / EMBRAPA - FLORESTAS \\ WREGE, Marcos Silveira - marcos.wrege@embrapa.br \\ Empresa Brasileira de Pesquisa Agropecuária / EMBRAPA - FLORESTAS
}

MANTOVANI, Luiz Eduardo - lemaels@ufpr.br

Universidade Federal do Paraná / UFPR

\begin{abstract}
RESUMO: Vários aspectos climáticos estão associados à presença natural da Araucaria angustifolia (Bert) $\mathrm{O}$. Kuntze, mas a importância relativa de cada um deles ainda não foi suficientemente explorada, e pode ser diferente nas diversas regiões nativas da araucária. Assim, o objetivo deste trabalho foi identificar os aspectos climáticos mais fortemente relacionados à presença da espécie no estado do Rio Grande do Sul. Para isto, foram separados os locais de ocorrência da araucária (acima de $450 \mathrm{~m}$ ) e foram utilizados os dados locais de temperatura, insolação, umidade relativa e disponibilidade hídrica. Os dados foram submetidos a testes estatísticos uni e multivariados para discriminar as variáveis climáticas onde a araucária, preferencialmente, se desenvolve. A araucária está adaptada aos locais de menores temperaturas, maior risco de ocorrência de geadas e maior disponibilidade hídrica. Outros fatores tais como umidade relativa, insolação e evapotranspiração no verão, caracterizando um verão mais ameno, também foram constatados. Neste trabalho, foi possível concluir que há quatro zonas distintas de ocorrência da araucária, uma na Serra do Sudeste, duas no Planalto Meridional e uma na Serra do Nordeste. Os conhecimentos obtidos permitem definir áreas distintas de conservação in situ e podem auxiliar na elaboração de programas de conservação e melhoramento genético.
\end{abstract}

PALAVRAS-CHAVES: clima; araucária, espécie nativa, floresta ombrófila mista.

THE NATURAL DISTRIBUTION OF THE BRASILIAN PINE IN THE STATE OF RIO GRANDE DO SUL, BRAZIL: THE CLIMATE INFLUENCE

ABSTRACT: Several climatic aspects are associated with the natural presence of Araucaria angustifolia (Bert) $\mathrm{O}$. Kuntze, but the relative importance of each of them has not yet been sufficiently explored. The objective of this work is to identify which climatic aspects are most strongly related to the presence of the species in state of Rio Grande do Sul. For this, the locations of brazilian-pine (above $450 \mathrm{~m}$ ) were isolated and the local data of temperature, insolation, relative humidity and water availability were used. The data were submitted to univariate and multivariate statistical tests to discriminate the climatic variables where brazilian-pine development occurs. Brazilian-pine is adapted to places of lower temperatures, greater risk of occurrence of frosts and greater water availability. Other factors such as relative humidity, summer insolation and summer evapotranspiration, characterizing a milder summer, were also observed. In this work, it was possible to conclude that there are four distinct areas of brazilian-pine occurrence, one in the Southeast, two in the Southern Plateau and one in the Serra do Nordeste. The knowledge obtained in this work allows to define different areas of conservation in situ and can help in the elaboration of programs of conservation and genetic improvement.

KEYWORDS: climate; Araucaria, native species, mixed ombrophilous forest.

\section{INTRODUÇÃO}

A Floresta Ombrófila Mista (FOM), ou Floresta com Araucaria, é caracterizada pela presença de Araucaria angustifolia (Bertol.) Kuntze que, por 
sua abundância, porte e copas corimbiformes, imprime o aspecto fitofisionômico próprio, sendo considerada uma formação típica do sul do país (VELOSO, 1992), embora sua ocorrência na província argentina de Missiones seja bastante significativa. A espécie é exclusiva da Floresta Ombrófila Mista (Floresta com Araucária) FOM, do bioma Mata Atlântica nas formações aluviais (galeria), Submontana, Montana e Alto Montana. Pode atingir mais de $50 \mathrm{~m}$ de altura e $250 \mathrm{~cm}$ de DAP (IBGE, 1992).

Até o início do século $X X$, as florestas com araucária compunham cerca de $35 \%$ da cobertura vegetal dos estados sulinos (GUERRA et al. , 2002) e se estendiam pelo Paraná $(40 \%)$, Santa Catarina (31\%) e Rio Grande do Sul (25\%), e a partir do sul de São Paulo para o norte, ocorriam de forma fragmentada, presentes em refúgios nas altitudes elevadas da Serra do Mar e da Mantiqueira, no planalto sudeste de São Paulo, sul de Minas Gerais, regiões serranas do Rio de Janeiro e Espírito Santo. Apesar de sua ampla distribuição geográfica, que ocorre entre as latitudes 19015'S (Conselheiro Pena, MG) a 31039' S (Canguçu, RS) e longitudes de 41030' a 54030' W e em altitudes que variam de 500 a $2300 \mathrm{~m}$, restaram apenas manchas esparsas e isoladas da espécie, o que levou a quase extinção (CARVALHO, 1994), a qual deve ser entendida como sendo a extinção das florestas primárias da FOM.

No Rio Grande do Sul, a Floresta Ombrófila Mista ocorre intercaladamente com áreas savânicas e estépicas, originando um sistema em mosaico, capões de mata, que caracteriza grande parte da paisagem da Região Sul do País (AUBREVILLE, 1949; KLEIN, 1960; 1984; HUECK, 1972; BACKES, 2001).

O Rio Grande do Sul é o estado mais meridional do Brasil e possui área de $281.730 \mathrm{~km}^{2}$, sendo o clima influenciado pelas condições de relevo, pela latitude, altitude e distância do mar. De acordo com a classificação climática de Köppen (1931), o clima é mesotérmico úmido - Cf, incluindo dois subtipos, Cfa e Cfb. O tipo "Cfa" apresenta a temperatura do mês mais quente superior ao "Cfb", que se restringe ao planalto basáltico superior e às áreas mais elevadas do escudo Sul-Rio-Grandense, ou seja, na Serra do Sudeste e Serra do Nordeste, onde as temperaturas médias dos meses de verão ficam abaixo dos $22^{\circ} \mathrm{C}$; e o tipo $\mathrm{Cfa}$, nas demais regiões, onde a temperatura média do mês mais quente ultrapassa os $22^{\circ} \mathrm{C}$. De acordo com Cordeiro e Hasenack (2009), o Rio Grande do Sul (RS) tem a vegetação distribuída em oito regiões fitoecológicas: Floresta Ombrófila Densa; Floresta Ombrófila Mista; Floresta Estacional Semidecidual; Floresta Estacional Decidual; Savana Estépica; Estepe; Área das Formações Pioneiras e Áreas de Tensão Ecológica, sendo que o condicionamento destas regiões no Rio Grande do Sul pode ser influenciado pela geologia, solos, paleoclimas e influência antrópica.

O avanço da fronteira agrícola e a urbanização, associado ao elevado valor comercial da madeira da araucária, levou-a à exploração indiscriminada, com forte redução da área original. Estima se que os remanescentes da Floresta Ombrófila Mista não perfazem mais do que $0,7 \%$ da sua área original no território brasileiro (MEDEIROS et al., 2005). Devido à redução em área de, pelo menos, $80 \%$ em 80 anos, a araucária poderia ser considerada ameaçada de extinção na categoria "Criticamente em perigo" (CR). No "Livro Vermelho da Flora do Brasil", ela está classificada como "Em perigo" (EN) por permanecer em 
unidades de conservação (UC) de proteção integral e apresentar alto potencial de cultivo (MARTINELLI; MORAES, 2013).

A Floresta Ombrófila Mista é uma das formações florestais mais sensíveis às variações climáticas. Devido a essa característica é possível correlacionar a sua presença a determinados paleoambientes (KLEIN, 1975; JOLY, 1998; LORENZI, 2002). Durante a época do Pleistoceno, iniciada a 2,588 milhões de anos durante o Período Quaternário, com fases de clima mais frio, a araucária (e a FOM) encontrava-se mais dispersa, em outras faixas de latitude e altitude. A partir do Holoceno, iniciado há 11.700 anos, com o retorno de clima mais quente e úmido (SALGADO-LABOURIAU, et al. 1998) houve favorecimento da expansão da Floresta Ombrófila Densa e da Floresta Estacional Semidecidual sobre a Floresta Ombrófila Mista (KLEIN, 1960; 1984). A distribuição disjunta das florestas em locais de maiores altitudes ou mais frias é evidência de uma distribuição mais ampla no passado e posterior regressão desta fisionomia sob o clima atual (ARZOLLA et al., 2014).

Nos dias atuais, o risco climático torna-se uma nova ameaça devido ao aquecimento global, pois a araucária está adaptada às regiões mais frias, de clima mais ameno, e as populações estabelecidas em locais limítrofes de temperatura poderão ser prejudicadas (WREGE et al., 2016), observadas as outras condições edafoclimáticas limitantes. Como para as espécies de ciclo de vida longo, entre as quais as florestais, o processo de adaptação deverá ser mais lento que a evolução das mudanças climáticas (HAMRICK, 2004), a maioria dos efeitos negativos causados pelo declínio e fragmentação das populações de A. angustifolia serão evidentes apenas após algumas gerações (WREGE et al., 2016).

Desta forma, a compreensão dos aspectos climáticos preferenciais para a araucária e onde é propício o seu desenvolvimento, pode ajudar na elaboração de estratégias que visem à conservação da espécie e da floresta com araucária e ao seu melhoramento para fins florestais, bem como seu manejo no presente e no futuro.

Assim, o objetivo deste trabalho é identificar quais aspectos climáticos estão relacionados à presença natural de $A$. angustifolia no estado do Rio Grande do Sul e verificar as diferenças climáticas entre as áreas onde a araucária ocorre atualmente $\mathrm{e}$, com isso, fornecer subsídios, tanto ao melhoramento genético e reconhecimento de biotipos, quanto ao estabelecimento das áreas para conservação in situ no estado.

\section{MATERIAL E MÉTODOS}

Para desenvolver este trabalho, foram reunidos os dados climáticos de 59 locais. Destes, foram separados locais onde não há presença de araucária (24) e onde a araucária ocorre em formações da FOM (35). Estes ultimos foram separados a partir de mapas da vegetação da distribuição da Floresta Ombrófila Mista no estado, onde ocorre a araucária e também pela altitude. Para os pontos onde não há araucária, foram separados municípios que se situavam acima de $361 \mathrm{~m}$ (Nova Palmira) até 486 metros (Não Me Toque). Foram excluídos os pontos abaixo de 361 metros, o que incluiu vários pontos próximos ao litoral, para que a análise focasse melhor as diferenças entre climas mais semelhantes 
e não tão distintos, como são os do litoral e calhas dos rios, quando comparados aos dos Planaltos e Serras.

Dos municípios onde a araucária ocorre, três situavam-se na Serra do Sudeste, e os demais a partir de 490 até $1053 \mathrm{~m}$ (Bom Jesus). Os dados climáticos dos pontos de ocorrência de araucária foram obtidos a partir da rede de estações meteorológicas do estado, cujas médias dos valores são apresentados no Atlas Climático da Região Sul do Brasil (WREGE et al., 2011). Nesse trabalho, o período base utilizado foi de 1976 a 2005. As temperaturas foram estimadas usando as regressões lineares múltiplas, as quais relacionam as variáveis climáticas com as coordenadas geográficas latitude, longitude e altitude para cada estação do ano e para o ano. A altitude de cada ponto de ocorrência de araucária, que era inexistente, foi obtida usando o modelo GTOPO30 do United State Geological Survey (USGS, 1999). Por essa técnica, foram calculados os valores de temperatura média do ar $\left({ }^{\circ} \mathrm{C}\right)$, médias das temperaturas mínimas, das temperaturas mínimas absolutas, das temperaturas máximas, das temperaturas máximas absolutas e da evapotranspiração potencial (etp, em $\mathrm{mm}$ ) para as quatro estações do ano - primavera, verão, outono, inverno e anual para cada ponto de ocorrência de araucária.

As médias da precipitação acumulada $(\mathrm{mm})$ por estação e por ano (p), da diferença p-etp $(\mathrm{mm})$, da insolação (horas) e da umidade relativa do ar (\%), para os mesmos pontos de ocorrência, foram obtidas pela interpolação dos dados, usando krigagem ordinária. Os valores destas variáveis foram transformados para o formato 'raster' e, posteriormente, foram extraídos em sistemas de informações geográficas, relacionando o mapa dos pontos de ocorrência da espécie com os mapas das variáveis climáticas.

Para a análise de agrupamento, foram selecionadas as seguintes variáveis depois de feita uma análise de componentes principais para verificar as de maior importância: temperatura máxima no verão, temperatura mínima no inverno, diferença entre precipitação e evapotranspiração no inverno e no verão, insolação de verão e de inverno, umidade relativa no verão e no inverno.

Os dados foram organizados em planilhas eletrônicas e submetidos primeiramente ao test $\mathrm{t}$ (teste de hipótese) e Mann Whitney (teste de medianas) para avaliar quais as variáveis climáticas eram significativamente diferentes entre os dois locais, com e sem araucária. O teste de Mann-Whitney (Wilcoxon rank-sum test) ou teste $U$ é indicado para comparação de dois grupos não pareados para se verificar se pertencem à mesma população e cujos requisitos para aplicação do teste $t$ de Student não foram cumpridos. $O$ teste $U$ pode ser considerado a versão não paramétrica do teste $t$, para amostras independentes. Ao contrário do teste $t$, que testa a igualdade das médias, $o$ teste de MannWhitney $(U)$ testa a igualdade das medianas. Os valores de $U$ calculados pelo teste avaliam o grau de entrelaçamento dos dados dos dois grupos após a ordenação. A maior separação dos dados em conjunto indica que as amostras são distintas, rejeitando-se a hipótese de igualdade das medianas.

Foram obtidos os valores médios e a amplitude de variação para as variáveis climáticas dos locais onde há presença de araucária, para fins de caracterização climática.

Os pontos onde há presença de araucária foram reunidos e foi feita a análise de agrupamento utilizando as variáveis climáticas já descritas. De 
acordo com MALLO (1985), a Análise de Cluster (agrupamento) tem por objetivo agrupar indivíduos em um número restrito de grupos ou classes homogêneas. 0 agrupamento é feito com base em uma similaridade ou uma distância estatística entre os elementos de uma matriz X (JOHNSON \& WICHERN, 1982). Essas medidas constituem a entrada de vários algoritmos e definem uma função dos valores dos vetores representativos dos elementos de $X$, para os quais se calcula uma medida de similaridade ou distância. Com o resultado da análise de agrupamento, foram subdivididos os locais onde há presença natural de araucária.

Depois de identificados os grupos, foram aplicados a ANOVA e o teste de Kruskal Wallis para verificar para quais variáveis climáticas os grupos se diferenciavam. Os testes de comparações múltiplas entre médias de tratamentos são de grande interesse na pesquisa aplicada, quando o objetivo do trabalho é comparar tratamentos qualitativos. A utilização de um teste é realizada quando a análise de variância detecta existência de efeito significativo dos tratamentos a um determinado nível de significância, de modo que se decide rejeitar a hipótese de nulidade (pelo menos um contraste ortogonal entre tratamentos diferentes de zero). Dentre os testes mais comuns para comprovação dos resultados experimentais, estão o Teste $\mathrm{F}$, utilizado para verificar se existe diferença significativa entre contrastes ortogonais dos tratamentos, e os testes de Tukey, Duncan, Dunnet e o teste LSD, normalmente utilizados para detalhar esta informação, permitindo mostrar, especificadamente, quais tratamentos diferem estatisticamente (SOUZA et al., 2012).

\section{RESULTADOS}

\section{SEPARAÇÃO, PELAS VARIÁVEIS CLIMÁTICAS, DAS ÁREAS COM E SEM ARAUCÁRIA NO ESTADO DO RIO GRANDE DO SUL}

As áreas com araucária se diferenciam das áreas sem araucária especialmente pelas temperaturas (temperaturas média anual, máxima de verão, da primavera e de outono; temperaturas mínimas de inverno, de primavera e de outono e temperatura mínima absoluta no inverno e máxima absoluta no verão). Nas regiões com araucária, as temperaturas mínimas absolutas são sempre menores, acompanhadas de maior frequência de risco de ocorrência de geadas comparadas às áreas com ausência de araucária.

A disponibilidade hídrica e a umidade relativa no verão são diferentes e onde a araucária ocorre são maiores, entretanto, a insolação no verão é menor (Tabela 1). 
Tabela 1 - Testes T e Mann Whitney para as variáveis climáticas nas áreas com aptidão climática para grupo com araucária (GCA) e grupo sem araucária (GSA).

\begin{tabular}{|c|c|c|c|c|c|c|c|c|}
\hline Variáveis & Teste $\mathrm{t}$ & valor $\mathrm{P}$ & $\begin{array}{l}\text { Mann } \\
\text { Whitney }\end{array}$ & valor $\mathrm{P}$ & $\begin{array}{l}\text { valor } \\
\text { médio } \\
\text { GSA }\end{array}$ & $\begin{array}{l}\text { amplitude } \\
\text { GSA }\end{array}$ & $\begin{array}{l}\text { valor } \\
\text { médio } \\
\text { GCA }\end{array}$ & $\begin{array}{l}\text { amplitude } \\
\text { GCA }\end{array}$ \\
\hline Altitude $(\mathrm{m})$ & 7,676 & $2,37 \mathrm{E}-8 *$ & 67 & $5,13 \mathrm{E}-8^{*}$ & 414 & $361-486$ & 690 & $239-1053$ \\
\hline Temp. média anual $\left({ }^{\circ} \mathrm{C}\right)$ & $-6,386$ & $3,09 \mathrm{E}-7 *$ & 736 & $0,000 *$ & 18,34 & $16,8-19,5$ & 16,9 & $14,8-18,3$ \\
\hline Temp. máxima verão $\left({ }^{\circ} \mathrm{C}\right)$ & $-7,461$ & $3,760 \mathrm{E}-7^{*}$ & 786 & $1,702 \mathrm{E}-8^{*}$ & 28,6 & $27,4-29,8$ & 27,0 & $24,6-28,46$ \\
\hline Temp. mínima de inverno $\left({ }^{\circ} \mathrm{C}\right)$ & $-4,989$ & $0,0000 *$ & 690 & $0,000 *$ & 9,21 & $7,48-10,3$ & 8,23 & $6,46-9,27$ \\
\hline Temp. mínima de primavera $\left({ }^{\circ} \mathrm{C}\right)$ & $-5,5623$ & $0,0000 *$ & 709 & $0,000 *$ & 13,2 & $11,4-14$ & 11,9 & $9,9-13$ \\
\hline Temp. mínima no outono $\left({ }^{\circ} \mathrm{C}\right)$ & $-6,166$ & $4,27 \mathrm{E}-7 *$ & 734 & $0,000 *$ & 13,8 & $12,5-15$ & 12,9 & $10,8-13,8$ \\
\hline Temp. máxima na primavera $\left({ }^{\circ} \mathrm{C}\right)$ & $-4,8187$ & $0,0000 *$ & 673 & $0,000 *$ & 23,9 & $21,7-25,5$ & 22,6 & $20,2-24,3$ \\
\hline Temp. máxima no outono $\left({ }^{\circ} \mathrm{C}\right)$ & $-5,753$ & $5,916 \mathrm{E}-7 *$ & 715 & $0,000 *$ & 24,2 & $22,5-25,4$ & 22,9 & $20,7-24,5$ \\
\hline Temp. mínima absoluta inverno $\left({ }^{\circ} \mathrm{C}\right)$ & $-6,52$ & $3,3940 \mathrm{E}-7 *$ & 742 & $7,308 \mathrm{E}-7 *$ & $-6,68$ & $-2,88-1,57$ & $-2,88$ & $-6,68-0,55$ \\
\hline Temp. máxima absoluta verão $\left({ }^{\circ} \mathrm{C}\right)$ & $-7,1033$ & $3,955 \mathrm{E}-7^{*}$ & 772 & $5,836 \mathrm{E}-8 *$ & 35,0 & $34,5-35,7$ & 33,8 & $32,0-35,7$ \\
\hline Risco de geada (\%) & 5,320 & $0,0000 *$ & 153 & $0,000 *$ & 0,59 & $0,44-0,77$ & 0,72 & $0,56-0,95$ \\
\hline Precipitação total anual ( $\mathrm{mm}$ ) & $-1,012$ & 0,3153 & 506 & 0,187 & 1775 & $1454-1962$ & 1732 & $1501-1904$ \\
\hline Precipitação de verão (mm) & 1,902 & 0,062 & 290 & $0,046 *$ & 432 & $356-500$ & 450 & $374-503$ \\
\hline Precipitação de inverno (mm) & 0,0066 & 0,9946 & 390 & 0,649 & 432 & $376-496$ & 432 & $373-497$ \\
\hline Disponibilidade hídrica verão (mm) & 5,406 & $0,0000 *$ & 106 & $0,000 *$ & 75 & $25-134$ & 128 & $23-231$ \\
\hline Disponibilidade hídrica inverno (mm) & 0,028 & 0,977 & 377 & 0,517 & 325 & $282-387$ & 325 & $282-368$ \\
\hline Evapotranspiração verão (mm) & $-7,1593$ & $4,1912 \mathrm{E}-7 *$ & 775 & $4,507 E-8 *$ & 357 & $328-383$ & 322 & $271-353$ \\
\hline Evapotranspiração inverno (mm) & $-0,1059$ & 0,9160 & 477 & 0,383 & 107 & $97-113$ & 107 & $93-116$ \\
\hline Insolação verão $(h)$ & $-5,239$ & $0,000 *$ & 706 & $0,000 *$ & 234 & $210-253$ & 216 & $187-243$ \\
\hline Insolação inverno (h) & $-0,638$ & 0,525 & 422 & 0,975 & 160 & $144-166$ & 159 & $141-168$ \\
\hline Umidade relativa verão (\%) & 4,510 & $0,0000 *$ & 152 & $0,000 *$ & 74 & $72-83$ & 76 & $67-77$ \\
\hline Umidade relativa inverno (\%) & $-0,5340$ & 0,5953 & 465 & 0,487 & 79 & $77-81$ & 79 & $77-82$ \\
\hline
\end{tabular}




\section{SEPARAÇÃO DOS GRUPOS COM ARAUCÁRIA NO ESTADO DO RIO GRANDE DO SUL}

Como resultado da análise de agrupamento das áreas com presença de araucária (Figura 1), verificou-se que elas podem ser divididas, primeiramente, em dois grupos principais, $A$ e $B$. O grupo $A$ que compõe os subgrupos $A 2$ e A11 e $A 12$ e no grupo $B$ não há subdivisão. Pode se verificar que os grupos $A 11$ e A12 ocorrem no Planalto Meridional. Deve ser observado que, neste trabalho, utilizaremos a denominação "grupos" também para os subgrupos, o A ocorre na Serra do Sudeste e o grupo B ocorre na Serra do Nordeste (Figura 2).

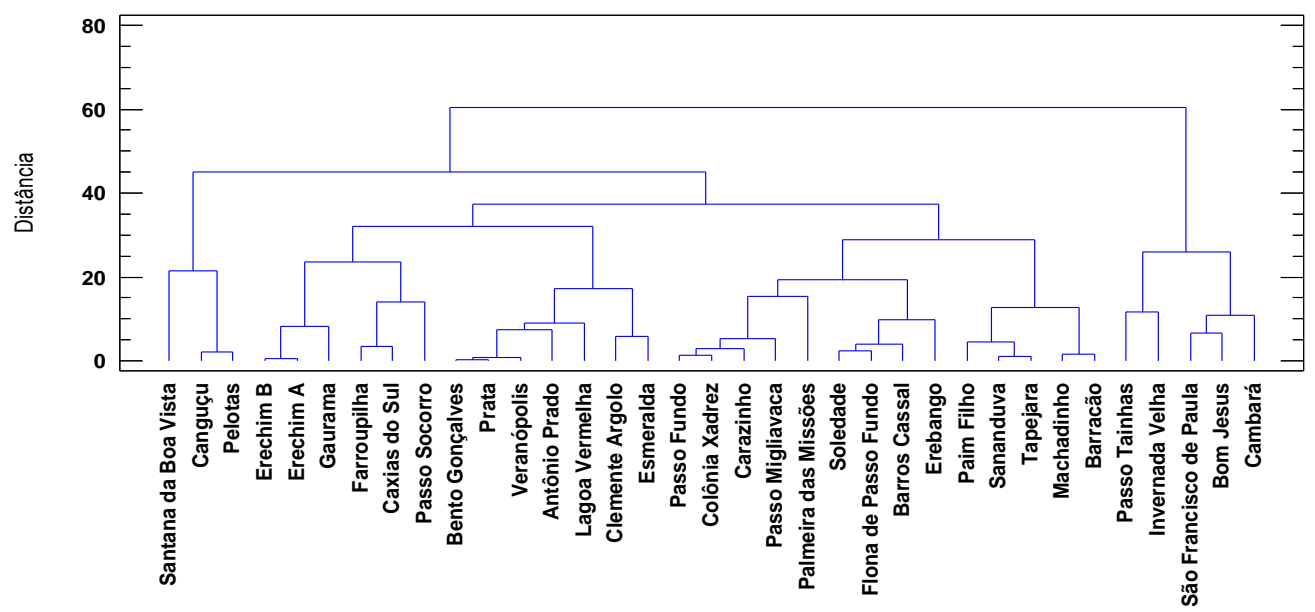

Figura 1 - Dendrograma para os locais com presença de araucária no estado do Rio Grande do Sul.

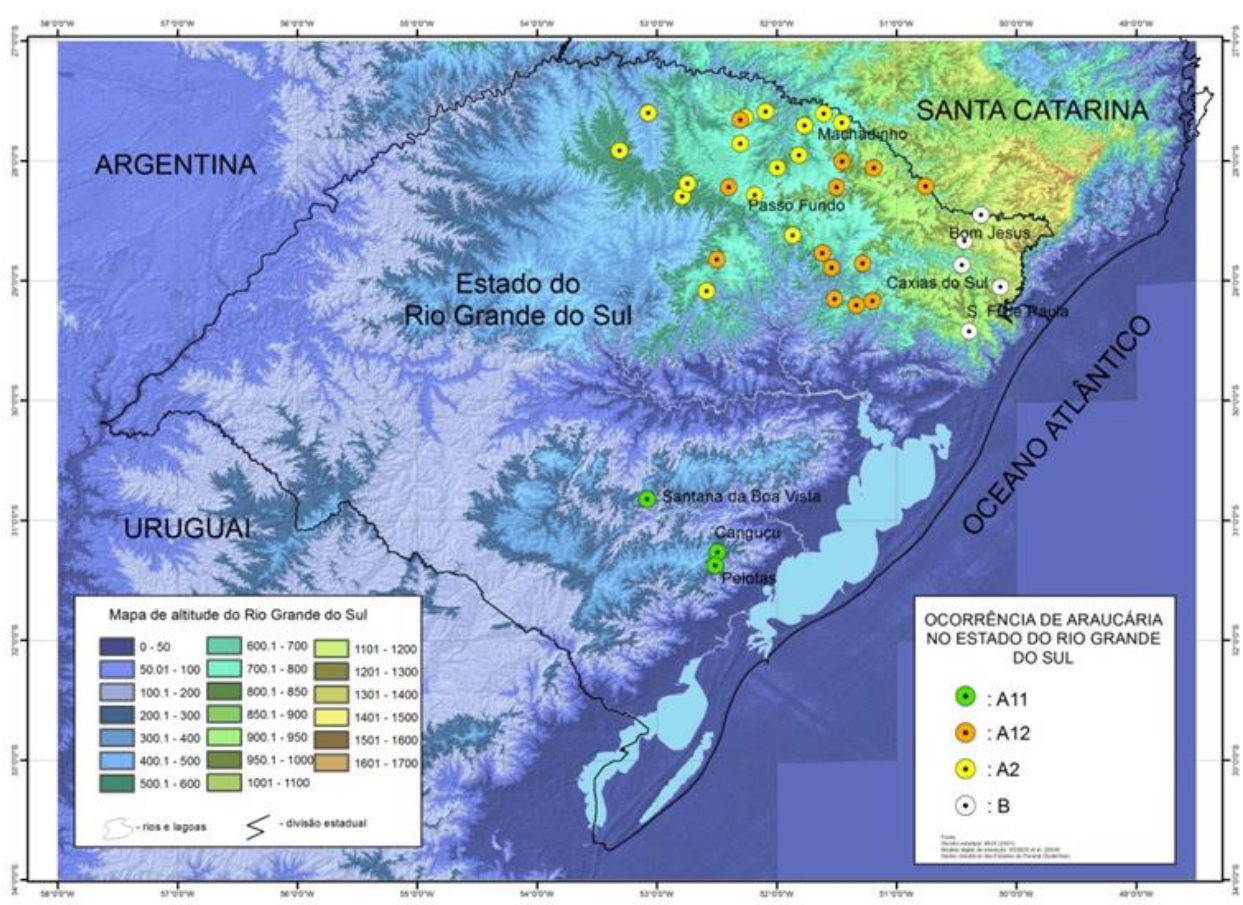


Figura 2 - Localização dos pontos com ocorrência de araucária.

Aplicando a ANOVA (one way) e Kruskal Wallis para os grupos para as mesmas variáveis utilizadas na análise de agrupamento, verificou-se que para todos os parâmetros houve diferenças entre os grupos (Tabela 2).

Tabela 2 - ANOVA e Kruskal Wallis com as variáveis climáticas utilizadas na análise de agrupamento.

\begin{tabular}{lllll}
\hline & Anova & \multicolumn{3}{c}{$\begin{array}{l}\text { Kruskal } \\
\text { Wallis }\end{array}$} \\
\cline { 2 - 5 } Variáveis & teste $\mathrm{F}$ & valor P & teste & valor P \\
\hline Temperatura máxima no verão $\left({ }^{\circ} \mathrm{C}\right)$ & 26,47 & $0^{*}$ & 23,59 & $0^{*}$ \\
Temperatura mínima no inverno $\left({ }^{\circ} \mathrm{C}\right)$ & 14,40 & $0^{*}$ & 16,73 & $0^{*}$ \\
P-ETP no verão $(\mathrm{mm})$ & 30,52 & $0^{*}$ & 18 & $0^{*}$ \\
P-ETP no inverno $(\mathrm{mm})$ & 24,56 & $0^{*}$ & 22,21 & $0^{*}$ \\
Insolação no verão $(\mathrm{h})$ & 42,64 & $0^{*}$ & 21,96 & $0^{*}$ \\
Insolação no inverno $(\mathrm{h})$ & 24,56 & $0^{*}$ & 20,99 & $0^{*}$ \\
Umidade relativa no verão $(\%)$ & 50,17 & $0^{*}$ & 0 & $0^{*}$ \\
Umidade relativa no inverno $(\%)$ & 11,47 & $0^{*}$ & 15,15 & 0,001 \\
Precipitação no inverno $(\mathrm{mm})$ & 30,93 & $0^{*}$ & 24,03 & $0^{*}$ \\
Precipitação no verão $(\mathrm{mm})$ & 20,55 & $0^{*}$ & 15,87 & $0^{*}$ \\
Altitude $(\mathrm{m})$ & 23,17 & $0^{*}$ & 16,25 & 0,001 \\
\hline
\end{tabular}

Nota: *significativo em nível de $5 \%$ de probabilidade

Aplicando-se teste de comparações múltiplas LSD, foram identificadas as variáveis que apresentaram diferenças significativas entre os grupos (tabela 3). Os grupos homogêneos estão situados na mesma coluna e, assim, observa-se que os opostos são os grupos A11, da Serra do Sudeste e o B da Serra do Nordeste (Figura 1 e Tabela 3), enquanto que os grupos A12 e A2, grupos do Planalto, apresentam maior proximidade. 
Tabela 3 - Intervalos múltiplos (LSD) para os grupos com as variáveis climáticas.

\begin{tabular}{|c|c|c|c|c|c|c|c|}
\hline Variável climática & $\begin{array}{l}\text { Grupos } \\
\text { formados }\end{array}$ & $\begin{array}{c}\text { Número de } \\
\text { componentes dos } \\
\text { grupos }\end{array}$ & $\begin{array}{l}\text { Média da } \\
\text { variável } \\
\text { climática }\end{array}$ & & $\begin{array}{l}\text { ru } \\
\text { om } \\
\text { ne }\end{array}$ & $\begin{array}{l}\text { pos } \\
\log 6 \\
\text { os }\end{array}$ & \\
\hline \multirow{4}{*}{$\begin{array}{c}\text { Temperatura } \\
\text { máxima no verão } \\
\left({ }^{\circ} \mathrm{C}\right)\end{array}$} & $B$ & 5 & 25,4 & $\mathrm{x}$ & & & \\
\hline & A12 & 13 & 26,8 & & $x$ & & \\
\hline & $\mathrm{A} 2$ & 14 & 27,5 & & & $\mathrm{x}$ & \\
\hline & A11 & 3 & 27,9 & & & $\mathrm{x}$ & \\
\hline \multirow{4}{*}{$\begin{array}{l}\text { Temperatura } \\
\text { mínima no } \\
\text { inverno }\left({ }^{\circ} \mathrm{C}\right)\end{array}$} & $B$ & 5 & 7,2 & $x$ & & & \\
\hline & A11 & 3 & 8,1 & & $\mathrm{x}$ & $x$ & \\
\hline & A12 & 13 & 8,1 & & $x$ & & \\
\hline & $\mathrm{A} 2$ & 14 & 8,7 & & & $x$ & \\
\hline \multirow{4}{*}{$\begin{array}{l}\text { P-ETP no verão } \\
(\mathrm{mm})\end{array}$} & A11 & 3 & 37 & $x$ & & & \\
\hline & A12 & 13 & 123 & & $\mathrm{x}$ & & \\
\hline & $\mathrm{A} 2$ & 14 & 130 & & $x$ & & \\
\hline & $\mathrm{B}$ & 5 & 191 & & & $\mathrm{x}$ & \\
\hline \multirow{4}{*}{$\begin{array}{l}\text { P-ETP no inverno } \\
(\mathrm{mm})\end{array}$} & $B$ & 5 & 286 & $\mathrm{x}$ & & & \\
\hline & A11 & 3 & 303 & $\mathrm{x}$ & & & \\
\hline & A12 & 13 & 323 & & $\mathrm{x}$ & & \\
\hline & $\mathrm{A} 2$ & 14 & 346 & & & $x$ & \\
\hline \multirow{4}{*}{$\begin{array}{l}\text { Insolação no } \\
\text { verão }(h)\end{array}$} & $\mathrm{B}$ & 5 & 191 & $\mathrm{x}$ & & & \\
\hline & A12 & 13 & 213 & & $\mathrm{x}$ & & \\
\hline & $\mathrm{A} 2$ & 14 & 222 & 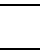 & & $\mathrm{x}$ & \\
\hline & A11 & 3 & 243 & & & & $x$ \\
\hline \multirow{4}{*}{$\begin{array}{l}\text { Insolação no } \\
\text { inverno }(\mathrm{h})\end{array}$} & $B$ & 5 & 144 & $x$ & & & \\
\hline & A11 & 3 & 147 & $x$ & & & \\
\hline & A12 & 13 & 159 & & $x$ & & \\
\hline & $\mathrm{A} 2$ & 14 & 165 & & & $x$ & \\
\hline \multirow{4}{*}{$\begin{array}{l}\text { Umidade relativa } \\
\text { no verão }(\%)\end{array}$} & A11 & 3 & 74 & $x$ & & & \\
\hline & $\mathrm{A} 2$ & 14 & 76 & & $x$ & & \\
\hline & A12 & 13 & 76 & & $\mathrm{x}$ & & \\
\hline & $\mathrm{B}$ & 5 & 81 & & & $\mathrm{x}$ & \\
\hline \multirow{4}{*}{$\begin{array}{l}\text { Umidade realtiva } \\
\text { no inverno }(\%)\end{array}$} & $A 2$ & 14 & 78 & $x$ & & & \\
\hline & A12 & 13 & 78 & $\mathrm{x}$ & & & \\
\hline & $B$ & 5 & 80 & & $x$ & & \\
\hline & A11 & 3 & 81 & & $x$ & & \\
\hline \multirow{4}{*}{$\begin{array}{l}\text { Precipitação no } \\
\text { verão }(\mathrm{mm})\end{array}$} & A11 & 3 & 375 & $\mathrm{x}$ & & & \\
\hline & A12 & 13 & 441 & & $\mathrm{x}$ & & \\
\hline & $\mathrm{A} 2$ & 14 & 465 & 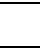 & & $\mathrm{x}$ & \\
\hline & $\mathrm{B}$ & 5 & 479 & & & $\mathrm{x}$ & \\
\hline \multirow{4}{*}{$\begin{array}{l}\text { Precipitação no } \\
\text { inverno }(\mathrm{mm})\end{array}$} & $B$ & 5 & 391 & $\mathrm{x}$ & & & \\
\hline & $A$ & 3 & 401 & $x$ & & & \\
\hline & A12 & 13 & 431 & & $x$ & & \\
\hline & $\mathrm{A} 2$ & 14 & 455 & & & $\mathrm{x}$ & \\
\hline \multirow{4}{*}{ Altitude (m) } & A11 & 3 & 299 & $x$ & & & \\
\hline & $\mathrm{A} 2$ & 14 & 656 & & $\mathrm{x}$ & & \\
\hline & A12 & 13 & 743 & & & $x$ & \\
\hline & $\mathrm{B}$ & 5 & 883 & & & & $x$ \\
\hline
\end{tabular}




\section{DISCUSSÃO}

\section{CARACTERÍSTICAS CLIMÁTICAS DAS ÁREAS COM ARAUCÁRIA NO ESTADO DO RIO GRANDE DO SUL}

Verificaram-se diferenças essenciais no clima das regiões com araucária quando comparado ao das outras regiões. Nas áreas com araucária, as temperaturas são sempre menores e o risco de ocorrência de geadas é maior. Isto está de acordo com KLEIN (1960) e PULCHALSKI et al., (2006). que afirmam que a araucária se distribui em amplas condições de ambientes, ocorrendo em variadas condições geológicas, pedológicas, geomorfológicas e climáticas, mas que sua presença é definida pelas condições climáticas, estando adaptada às regiões de menores temperaturas e com ocorrência de geadas. A ocorrência é muito influenciada pelas condições de relevo local, sendo favorecidos os compartimentos geomorfológicos mais côncavos ou abaciados que propiciam o acúmulo de ar frio durante eventos de inversão térmica na baixa atmosfera. Desta forma, mais importante que as condições de solos, o clima é fator condicionante no estabelecimento da araucária (PULCHALSKI et al., 2006). Observa-se que a araucária ocupa diferentes condições pedológicas, resultados de solos de diversas origens litológicas, desde as rochas do embasamento cristalino do escudo rio-grandense até as do planalto basáltico ao norte e nordeste do estado, além de estratos sedimentares.

PULCHALSKI et al. (2006) afirmam que nas condições climáticas onde as temperaturas médias anuais são maiores do que as existentes na área de ocorrência natural, existe interferência no ciclo reprodutivo da espécie, impedindo sua regeneração natural e estabelecimento, visto que em climas mais quentes não se encontram populações naturais e, ainda que, nessas condições, ocorrem outras espécies com crescimento mais vigoroso e mais competitivas do que a araucária. As maiores temperaturas médias no estado ocorrem no Litoral Norte, Depressão Central e Fronteira Oeste, onde existe a calha do Uruguai e onde são encontrados outros tipos de formações vegetais. Nas regiões mais altas, como no Planalto Nordeste, predominam temperaturas menores, onde é observada a ocorrência da araucária.

A região da Floresta com Araucária é bem delimitada por clima temperado, com alto índice de chuvas e com geadas frequentes, sendo coincidente à isoterma de $18{ }^{\circ} \mathrm{C}$ (BACKES, 1999). Entretanto, para o Rio Grande do Sul, a araucária ocorre nas regiões onde a temperatura média anual é inferior a esse valor, estando entre 15 e $18^{\circ} \mathrm{C}$ e com valor médio de $17^{\circ} \mathrm{C}$ (TABELA 1). A temperatura média mensal da região de ocorrência da araucária pode atingir valores inferiores a $10^{\circ} \mathrm{C}$ nos meses mais frios e pouco superiores a $20{ }^{\circ} \mathrm{C}$ nos meses mais quentes (MAACK, 1981; BACKES, 2009). Neste trabalho, a média das temperaturas mínimas de inverno situou-se entre 6,5 a $9,3^{\circ} \mathrm{C}$, com valor médio de $8,2^{\circ} \mathrm{C}$ e a média das temperaturas máximas de verão situou-se entre 24,6 a $28,5^{\circ} \mathrm{C}$, com valor médio de $27^{\circ} \mathrm{C}$.

Nas áreas onde a araucária ocorre, a precipitação pluviométrica varia de 1500 até $1900 \mathrm{~mm}$ acumulados em um ano, na média, estando em uma faixa intermediária de precipitação para o estado, cujos valores variam de 1200 a 2400 mm (Wrege et al. 2011). Golfari et al (1978) afirmam que a araucária não tolera seca e que, embora ocorra em regiões com geadas frequentes, isso não 
constitui exigência da espécie. Os autores citados também afirmam que, onde ocorre araucária na região sul, as precipitações variam entre 1250 e 2000 mm, sendo periódicas e sem estiagem no inverno ou no verão; apresentam-se com maior umidade relativa do ar e disponibilidade hídrica, se comparada às áreas onde não ocorre araucária. Na média, onde a espécie ocorre, a umidade relativa do ar no verão é de $76 \%$ e, nas áreas sem araucária, é de 74\%. No estado, entre a região mais seca e a mais úmida, ocorrem variações entre 64 e 88 \%.

Nas regiões com araucária, a insolação é menor, se comparada às áreas sem ocorrência. O valor médio mensal de insolação no verão nas áreas com araucária é de 216 h e, nas áreas sem ocorrência, é de 234 h. No estado, os valores de insolação variam de 160 a 270 h ( WREGE et al, 2011).

Segundo Maack (1981), a distribuição contínua da araucária tem seu limite altitudinal inferior de ocorrência de 500 m (para os estados de Paraná e Santa Catarina), abaixo do qual a espécie só ocorre de forma descontínua e nas linhas de escoamento de ar frio. Roderjan et al. (2002) afirmam que na cota de 650-700 m aparecem as araucárias no Paraná e, em São Paulo, acima dos 750 a $800 \mathrm{~m}$. Dessa forma, uma menor latitude é compensada com uma altitude maior, justificando a ocorrência de araucária nos estados de Santa Catarina e do Rio Grande do Sul em altitudes menores. Neste trabalho, a menor altitude encontrada foi de $236 \mathrm{~m}$ na Serra do Sudeste. A maior altitude foi de $1053 \mathrm{~m}$ na Serra do Nordeste.

A Serra do Sudeste, ou escudo Rio Grandense, se estende entre as latitudes $30^{\circ} \mathrm{S}$ e $32^{\circ} \mathrm{S}$ e alcança altitudes de até $550 \mathrm{~m}$, ela também é chamada de Escudo Sul-Riograndense ou Escudo Cristalino, devido a sua composição geológica ser principalmente de granito, embora gnaisse e arenito conglomerático também sejam encontrados na região (RAMBO, 1956; DUTRA \& STRANZ, 2003).

Reitz et al. (1983) consideram que o limite sul da Floresta com Araucária está nesta serra, especificamente em Canguçu, na latitude de $31^{\circ} \mathrm{S}$. Backes (1988, 1999); Dutra e Stranz (2003) também indicam que os núcleos de Floresta com Araucária da Serra do Sudeste são pequenos, mas fitogeograficamente importantes. De acordo com Carlucci et al. (2011), caso as araucárias pertencentes ao limite sul da Serra do Sudeste sejam consideradas nativas, haveria uma ocorrência disjunta da espécie e, talvez, do tipo vegetacional Floresta com Araucária. Em outras palavras, a espécie e a formação ocorreriam no norte, desde os núcleos pequenos e esparsos da Serra do Mar e da província de Missiones, passando pelas áreas maiores e mais contínuas do Paraná, de Santa Catarina e do Rio Grande do Sul, até a borda meridional do Planalto Sul brasileiro (ocorrência amplamente aceita pela comunidade científica), até seu verdadeiro limite sul, nos núcleos da Serra do Sudeste no Rio Grande do Sul (separados do restante da área de ocorrência pela Depressão Central gaúcha).

Quanto à temperatura, sabe-se que é influenciada pela altitude e latitude e, normalmente, decresce com o aumento da altitude numa proporção de aproximadamente $1^{\circ} \mathrm{C} / 100 \mathrm{~m}$ (gradiente adiabático do ar seco). Esta taxa de arrefecimento ocorre, pois uma massa de ar em ascensão está sujeita a pressão cada vez menor, aumentando seu volume e diminuindo a temperatura. Como este gradiente térmico depende da umidade relativa do ar, diminuindo quando o ar começa a se saturar por liberação de calor latente de condensação, o 
decréscimo da temperatura média com a altitude situa-se em torno de $1^{\circ} \mathrm{C}$ a cada 180 metros (DURY, 1972).

No Paraná, Maack (1981) cita a alteração de $0,5^{\circ} \mathrm{C}$ para cada 100 metros e, na média, Ometto (1981) cita a alteração de $0,6^{\circ} \mathrm{C}$ para cada $100 \mathrm{~m}$ de altitude. Assim, nas regiões de latitudes médias, como é o caso do Paraná, as grandes diferenças de temperatura em pequenas distâncias decorrem dos efeitos da variação da altitude e nebulosidade, podendo haver também grandes diferenças nas condições de temperatura entre os locais a barlavento e os situados a sotavento de uma montanha (OMETTO, 1981).

Mesmo em zonas subtropicais, Cagnelutti et al. (2006) concluíram que a altitude exerce maior influência que a latitude para o estado do Rio Grande do Sul. Em estudo feito para o estado do Rio Grande do Sul, FRITZSONS et al. (2008) verificaram que o gradiente térmico médio obtido para o conjunto de todas as estações meteorológicas do estado foi de, aproximadamente, $0,75^{\circ} \mathrm{C}$ a cada 100 metros de altitude e para o grupo das estações meteorológicas presentes na Serra do Nordeste, foi de $0,9^{\circ} \mathrm{C}$.

Os locais onde estão presentes as araucárias foram divididos em quatro grupos pela análise de agrupamento e eles estão localizados geograficamente: Serra do Nordeste (B), Serra do Sudeste (A11) e dois grupos no Planalto Meridional (A12 e A2). Todos estes locais apresentam em comum o fato de serem localizados em clima Cfb e não no Cfa e o fato das araucárias ocorrerem no clima Cfb é coerente com a classificação de Köppen-Geiger, pois este sistema de classificação é o mais utilizado em geografia, climatologia e ecologia e a classificação é baseada no pressuposto, com origem na fitossociologia e na ecologia, de que a vegetação natural de cada grande região de nosso planeta é essencialmente uma expressão do clima nela prevalecente (ROLIM et al., 2007). Assim, os divisores entre regiões climáticas foram selecionados para corresponder, tanto quanto possível, às áreas de predominância de cada tipo de vegetação, razão pela qual a distribuição global dos tipos climáticos e a distribuição dos biomas apresenta elevada correlação. No entanto, existem diferenças no clima dentro do domínio do clima Cfb e que outras classificações, baseadas em critérios diferentes da classificação de Koeppen, as identificam. Neste sentido, Rossato (2011) desenvolveu um estudo mais detalhado do clima do Rio Grande do Sul e o colocou em "Área de domínio de Clima subtropical", subdividido em quatro tipos, sendo que esta divisão foi baseada em umidade e diferença das temperaturas no inverno e verão, considerando também a amplitude longitudinal do estado.

A amostragem de pontos de ocorrência de araucária na Serra do Sudeste foi suficiente para caracterizar o clima. Verificou-se que o clima da região se diferenciou dos outros grupos em vários aspectos: menores precipitações no inverno e no verão, bem como menores disponibilidades hídricas e umidade relativa do ar. A insolação é maior no verão e menor no inverno, a precipitação pluviométrica é menor no inverno e no verão, e as temperaturas, no verão, são maiores (Tabela 3). Estas informações conferem com os mapas de Wrege et al. (2011) e estão relacionadas a um clima mais meridional, apesar de ainda Cfb, onde, no verão, o fotoperíodo é maior, repercutindo em maiores insolação e evapotranspiração no verão.

Na Serra do Sudeste, a menor altitude pode ser compensada pela maior latitude, pois a araucária ocorre nos municípios de Santana da Boa Vista, 
Canguçu e Pelotas, em altitudes de 239, 291 e 369 m, respectivamente. O clima é o Cfb, da classificação de Köppen, o qual ocorre também nas porções mais elevadas da Serra do Nordeste e Planalto (KUINCHTNER e BURIOL, 2001).

A amostragem da Serra do Nordeste (grupo B) representa o grupo mais diferente dentre todos, pois está em altitude média superior aos demais (883 $\mathrm{m}$ ) e apresenta-se com as menores temperaturas, tanto as máximas de verão quanto as mínimas de inverno; menor insolação no verão e no inverno, maior umidade relativa do ar no verão e no inverno, maior disponibilidade hídrica no verão e, menor, no inverno. As altitudes da Serra do Nordeste são as maiores do estado e na amostragem deste trabalho vai de $635 \mathrm{~m}$, em Passo Tainhas, a 1053 m, em Bom Jesus. Na Serra do Nordeste, parte meridional da Serra Geral assentada sobre rochas basálticas, ocorre neve com alguma raridade, entre as altitudes de 900 a 1.400 m, denominadas de Campos de Cima da Serra, onde juntamente com Santa Catarina estão os municípios mais frios do país. As derivações mais ácidas do magmatismo basáltico tendem a sustentar os compartimentos mais elevados do planalto tal como ocorre na Serra do Nordeste. Todo o estado está sujeito às fortes geadas, mas estas são mais comuns nas regiões de altitudes maiores, ocorrendo com menor frequência na Depressão Central e no Vale do Uruguai.

Os grupos A12 e A2 localizam-se no Planalto Meridional, possuem altitudes semelhantes e próximas às do grupo $B$. No grupo A12 predominam altitudes maiores que no grupo A2.

\section{CONCLUSÕES}

Nas áreas em que a araucária ocorre no estado do Rio Grande do Sul, as variáveis climáticas mais importantes são as temperaturas menores, maior risco de geadas, maiores disponibilidade hídrica e umidade relativa do ar no verão, menores insolação e evapotranspiração potencial, caracterizando verões mais amenos.

No estado do Rio Grande do sul, ocorrem pontos de distribuição em três locais distintos geograficamente: Serra do Nordeste, Serra do Sudeste e Norte do Planalto Meridional, sendo que no Planalto Meridional há uma diferença entre áreas de maior altitude e as de menor altitude. Estas três regiões apresentam clima diferenciado, apesar de se situarem na mesma zona de classificação climática por Koeppen, Cfb.

Devido às diferenças de clima nestes locais, existe a possibilidade de ocorrerem populações diferentes de araucária e, assim, este trabalho é bastante útil para definir áreas de conservação in situ da floresta com araucária.

Programas de conservação genética podem ser orientados para verificar diferenças genotípicas entre os grupos, na tentativa de correlacionar a distribuição geográfica e diversidade genética. Estudos pedológicos poderiam também indicar combinações edafoclimáticas mais favoráveis.

\section{REFERÊNCIAS BIBLIOGRÁFICAS}

ARZOLLA et al. Porque tombar imediatamente a Serra da Mantiqueira no Estado de São Paulo. Governo do Estado de São Paulo. Disponível em: 
http://iflorestal.sp.gov.br/2014/05/06/porque-tombar-imediatamente-a-serrada-mantiqueira-no-estado-de-sao-paulo/

AUBREVILLE, A. A floresta de pinho do Brasil. Anais Brasileiros de Economia Florestal. v. 2, n. 2, p. 21-36, 1949.

BACKES, A.; NARDINO, M. Árvores, arbustos e algumas lianas nativas no Rio Grande do Sul . São Leopoldo, Editora Unisinos.

BACKES, A. Condicionamento climático e distribuição geográfica de Araucaria angustifolia. (Bertol.) Kuntze no Brasil - II. Pesquisas - Botânica, v. 49, p. 31$51,2003$.

BACKES, A. Condicionamento climático e distribuição geográfica de Araucaria angustifolia (Bertol.) Kuntze no Brasil - II. Pesquisas, Série Botânica v. 49, p. 31-51, 1999.

BACKES, A. Determinação da idade e regeneração natural de uma população de Araucaria angustifolia (Bertol.). Kuntze em um povoamento florestal localizado no município de Caxias do Sul, RS, Brasil. Iheringia, Série Botânica v. 56, p. 115-130, 2001.

BACKES, P.; IRGANG, B. Árvores do Sul: guia de identificação \& interesse ecológico: as principais espécies nativas sul-brasileiras. [Rio de Janeiro]: Instituto Souza Cruz, 2002. 325 p.

CARGNELUTTI FILHO, A.; MALUF, J. R. T; MATZENAUER, R.; STOLZ, Á. P. Altitude e coordenadas geográficas na estimativa da temperatura mínima média decendial do ar no Estado do Rio Grande do Sul. Pesquisa Agropecuária Brasileira, Brasília, v. 41, n. 6, p. 893-901, 2006.

CARVALHO, P. E. R. Espécies florestais brasileiras: recomendações silviculturais, potencialidades e uso da madeira. Colombo: EMBRAPA - CNPF; Brasília: EMBRAPA - SPI, 1994. 640 p.

CORDEIRO, J. L. P.; HASENACK, H. Cobertura vegetal atual do Rio Grande do Sul. Disponível em: http://www.ecologia.ufrgs.br/labgeo/arquivos/Publicacoes/Livros_ou_capitulos/ 2009/Cordeiro_\&_Hasenack_2009_Cobertura_vegetal_RS.pdf. Acesso em: $17 / 03 / 2017$.

DURY, G. H. High temperature extremes in Australia. Annals of the Association of American Geographers. v. 62, n. 3, p. 388-400, 1972.

DUTRA TL; STRANZ A. História das Araucariaceae: a contribuição dos fósseis para o entendimento das adaptações modernas da família no Hemisfério Sul, com vistas a seu manejo e conservação. In: Ronchi LH \& Coelho OGW, editores. Tecnologia diagnóstico e planejamento ambiental. São Leopoldo: UNISINOS. p. 293-351, 2003.

FRITZSONS, E.; MANTOVANI, L. E. Relação entre altitude e temperatura: uma contribuição ao zoneamento climático no estado do Paraná. Revista de Estudos Ambientais. v. 10, n. 1, p. 49-64, 2008.

GOLFARI, L.; CASER, R. L.; MOURA, V. P. G. Zoneamento ecológico esquemático para reflorestamento no Brasil. Belo Horizonte: 1978. 66 p. PRODEPEF, PNUD/ FAO/IBDF/BRA-45. (Série Técnica, 11). 
GUERRA, M. P. et al. Exploração, manejo e conservação da araucária (Araucaria angustifolia). In: SIMÕES, L. L.; LINO, C. F. (Eds.). Sustentável Mata Atlântica: A exploração de seus recursos florestais. São Paulo: SENAC, 2002. p. 85-102.

HAMRICK, D.L. Response of tree to global environmental damages. Forest Ecology and Management. v. 194, p. 323-335, 2004.

HUECK, K. As florestas da América do Sul: ecologia, composição e importância econômica. São Paulo, Polígono. 1972.

IBGE. Manual técnico da vegetação brasileira (IBGE, ed.), Rio de Janeiro. 92 p., 1992.

JOHNSON, R. A.; WICHERN, D. W. Applied multivariate statistical analysis. Madison: Prentice Hall International, 1982. 607 p.

JOLY, A.B. Botânica: Introdução à taxonomia vegetal. Companhia Editora Nacional. São Paulo, 12 ed. 1998.

KLEIN, R. O aspecto dinâmico do pinheiro brasileiro. Sellowia, v. 12, p.17-48, 1960.

KLEIN, R.M. Southern Brazilian Phytogeographic Features and Probable Influence of upper Quaternary Climatic Changes in the Floristic Distribution. INTERNATIONAL SYMPOSIUM ON THE QUATERNARY. Boletim Paranaense de Geociências, n.33, 1975.

KLEIN, R.M. Aspectos dinâmicos da vegetação do sul do Brasil. Sellowia, Itajai, v. 36, p. 5-54, 1984.

KÖPPEN, W. Climatologia. México, Fundo de Cultura Econômica, 1931.

KUINCHTNER, A.; BURIOL, G. A. Clima do estado do Rio Grande do Sul segundo a classificação climática de Köppen e Thornthwaite. Disciplinarum Scientia. Série: Ciências Exatas, v.2, n.1, p. 171-182, 2001.

LORENZI, H. Árvores Brasileiras: manual de identificação e cultivo de plantas arbóreas nativas do Brasil. Nova Odessa, SP: Instituto Plantarum, 2 ed, v.1, v.2. 2002.

MAACK, R. Geografia física do Estado do Paraná. Rio de Janeiro: Livraria José Olympio Ed., 1981, 442 p.

MAACK, R. Mapa fitogeográfico do Estado do Paraná. Curitiba: IBPT-SAIC/INP. Um mapa 115 x $80 \mathrm{~cm}$. 1:750.000. 1950.

MALLO, F. Análisis de componentes principales y tecnicas factoriales relacionadas: teoria, computacion y aplicaciones. Leon: Universidad de Leon, 1985, $523 \mathrm{p}$.

MARTINELLI, G.; MORAES, M. A. (Eds.). 2013. Livro Vermelho da Flora Brasileira. Rio de Janeiro: Andrea Jakobson Estúdio; Instituto de Pesquisas Jardim Botânico do Rio de Janeiro, 1100 p.

MEDEIROS, J.D., SAVI, M.; BRITO, B. F. A. Seleção de áreas para criação de Unidades de Conservação na Floresta Ombrófila Mista. Biotemas. v.18, p. 33-50, 2005.

OMETTO. J. C. Bioclimatologia vegetal. São Paulo: Ed. Agronômica Ceres. 1981. 129-132 p. 
PUCHALSKI, A.; MANTOVANI, M.; REIS, M.S. dos. Variações em populações naturais de Araucaria angustifolia (Bert.) O. Kuntze associada a condições edafoclimáticas. Scientia Florestalis, v. 70, p.137-148, 2006.

RAMBO B, A fisionomia do Rio Grande do Sul. Porto Alegre: Selbach. 1956.

REITZ, R.; KLEIN, R. M.; REIS, A. Projeto Madeira do Rio Grande do Sul. Porto Alegre: Secretaria de Agricultura e Abastecimento, 1983, 524 p.

RODERJAN, C.V.; GALVÃO, F.; KUNIYOSHI, Y. S.; HATSCHBACK, G. As unidades fitogeográficas do estado do Paraná. Ciência e Ambiente. v.24, p. 75-92, 2002.

ROLIM, G. de S.; CAMARGO, M. B. P. de; LANIA, D. G.; MORAES, J. F. L. de. Classificação climática de Köppen e de Thornthwaite e sua aplicabilidade na determinação de zonas agroclimáticas para o estado de são Paulo. Bragantia [online]. 2007, v. 66, n.4, p. 711-720. ISSN 0006-8705. http://dx.doi.org/10.1590/S0006-87052007000400022.

ROSSATO, M. S. Os Climas do Rio Grande do Sul: variabilidade, tendências e tipologia. Tese de Doutorado apresentado ao Programa de Pós-graduação em Geografia/IGEO/UFRGS, Porto Alegre, 2011.

SALGADO-LABOURIAU, M.L., BARBERI, M., VICENTINI, K.R.F.; PARIZZI, M.G. A dry climatic event during the late quaternary of tropical Brazil. Review of Palaeobotany and Palynology. v. 99, p. 115-129, 1997.

SOUSA, C. A. de; LIRA JUNIOR, M. A.; FERREIRA, R. L. C. Avaliação de testes estatísticos de comparações múltiplas de médias. Revista Ceres, Viçosa , v. 59, n. 3, p. 350-354, 2012 Disponível em: <http://www.scielo.br/scielo.php?script=sci_arttext\&pid=S0034-

737X2012000300008\&lng=en\&nrm=iso>. Acesso em 09 mar. 2017. http://dx.doi.org/10.1590/S0034-737X2012000300008.

VELOSO, H.P.; RANGEL FILHO, A.L.R.; LIMA, L.C.A. Classificação da vegetação brasileira, adaptada a um sistema universal. Rio de Janeiro, IB, 1991.

WREGE, M. S.; SOUSA, V. A.; FRITZSONS, E.; SOARES, M.T.S.; AGUIAR, A.V. Predicting current and future geographical distribution of Araucaria niche modeling. Environmetal and Ecology Research, v. 4, p. 269-279, 2016.

WREGE, M. S; FRITZSONS, E. Dados climáticos dos municípios da região Sul do Brasil [recurso eletrônico] / Colombo: Embrapa Florestas, 2015. (Documentos / Embrapa Florestas, ISSN 1980-3958; 290.

WREGE, M.S.; STEINMETZ, S.; REISSER JR, C.; ALMEIDA, I.R. Atlas Climático da Região Sul do Brasil: Estados do Paraná, Santa Catarina e Rio Grande do Sul. Pelotas: Embrapa Clima Temperado; Colombo: Embrapa Florestas, 2011. 336 p. 